\title{
Synthesis and Electrochemical Characterization of Mesoporous $\mathrm{MnO}_{2}$
}

\author{
Jia Chang Zhao, Jun Wang, and Jing Li Xu \\ College of Chemistry and Chemical Engineering, Shanghai University of Engineering Science, Shanghai 201620, China \\ Correspondence should be addressed to Jia Chang Zhao; zjc@sues.edu.cn
}

Received 19 June 2014; Revised 5 November 2014; Accepted 6 November 2014

Academic Editor: A. K. Arof

Copyright (C) 2015 Jia Chang Zhao et al. This is an open access article distributed under the Creative Commons Attribution License, which permits unrestricted use, distribution, and reproduction in any medium, provided the original work is properly cited.

\begin{abstract}
The pore, crystal structure, and electrochemical performance of mesoporous $\mathrm{MnO}_{2}$ prepared by silica sol template method as electrode material for supercapacitor were investigated in this work. It is found that the crystal structure of nonporous and mesoporous $\mathrm{MnO}_{2}$ is confirmed to be $\beta-\mathrm{MnO}_{2}$ and the crystallinity of mesoporous $\mathrm{MnO}_{2}$ decreases due to the formation of mesopore. The results of electrochemical performance show that the specific capacitances of the sample prepared by using $20 \mathrm{~g}$ of $\mathrm{Mn}\left(\mathrm{NO}_{3}\right)_{2}$ solution and $40 \mathrm{~g}$ of silica sol (named MMO-4) at the scan rate of $5 \mathrm{mV} / \mathrm{s}$ are the highest (163.2 F/g), in comparison with $19.3 \mathrm{~F} / \mathrm{g}$ of that of the sample of blank, suggesting the important role of pore-forming using silica sol as template. As the potential scan rate is raised to $200 \mathrm{mV} / \mathrm{s}$, the specific capacitances of the sample of blank and MMO-4 are $12.2 \mathrm{~F} / \mathrm{g}$ and $21.6 \mathrm{~F} / \mathrm{g}$, respectively. The great improvement of specific capacitance is probably due to the enlarged activated surface area after template is added.
\end{abstract}

\section{Introduction}

$\mathrm{MnO}_{2}$ used as the key component of electrode for supercapacitor has been widely studied in recent years. $\mathrm{MnO}_{2}$ electrode material has been prepared by various methods, such as the sol-gel route [1], hydrothermal method [2], electrochemical deposition [3], microemulsion method [4], and sonochemistry method [5]. Recently, mesoporous $\mathrm{MnO}_{2}$ has been prepared by various methods and used as the electrode material for supercapacitor [6-10]. And the unique mesopore system and large surface area are expected to favor ion transfer in the pore system and increase the $\mathrm{MnO}_{2}$, electrolyte interfacial area, respectively, and thus can improve the electrochemical performance of the $\mathrm{MnO}_{2}$ electrode material. Silica sol as hard template has been widely used as the template for the synthesis of mesoporous polymer [11], mesoporous inorganic oxide [12], mesoporous carbon [13], and mesoporous metal [14]. In this paper, mesoporous $\mathrm{MnO}_{2}$ was synthesized by utilizing $\mathrm{Mn}\left(\mathrm{NO}_{3}\right)_{2}$ as manganese source and silica sol as template. And the electrochemical performance was investigated by cyclic voltammetry and chronopotentiometry.

\section{Experimental}

2.1. Reagents and Solutions. $\mathrm{Mn}\left(\mathrm{NO}_{3}\right)_{2}$ solution (50 wt.\%) was purchased from Shanghai Chemical Reagent Co. Ltd. and silica sol (20 wt.\%) with average particle size of $10 \mathrm{~nm}$ was purchased from Shanghai Debang Company.

2.2. Materials Preparation. Silica sol was added to $\mathrm{Mn}\left(\mathrm{NO}_{3}\right)_{2}$ solution and mixed thoroughly. The mixture was condensed to form precursor after the evaporation of water. And the precursor was heated up to $300^{\circ} \mathrm{C}$ at a rate of $5^{\circ} \mathrm{C} / \mathrm{min}$ and maintained for $2 \mathrm{~h}$. The obtained products were first washed by $3 \mathrm{M} \mathrm{KOH}$ solution for $10 \mathrm{~h}$ and then by deionized water until $\mathrm{pH}$ reached 7 . The mass of manganese source $\left(\mathrm{Mn}\left(\mathrm{NO}_{3}\right)_{2}\right)$ solution was fixed at $20 \mathrm{~g}$, whereas that of silica sol was $10,20,30,40,50$, and $60 \mathrm{~g}$, respectively. The $\mathrm{MnO}_{2}$ prepared by the decomposition of $\mathrm{Mn}\left(\mathrm{NO}_{3}\right)_{2}$ without template was designated as blank. And those synthesized with silica sol were designated as MMO-1, MMO-2, MMO3, MMO-4, MMO-5, and MMO-6 accordingly.

2.3. Instrumentation. The pore characteristics of the mesoporous $\mathrm{MnO}_{2}$ were measured on a Micromeritics (ASAP 
2010) instrument, using nitrogen at $77 \mathrm{~K}$. Mesopore size distributions were determined by BJH method. The micropore volume $\left(V_{\text {mic }}\right)$ and the total pore volume $\left(V_{t}\right)$ were calculated from the amount of $\mathrm{N}_{2}$ adsorbed at a relative pressure $\left(P_{r}=P / P_{0}\right)$ of 0.1 and 0.95 , respectively, and the mesopore volume $\left(V_{\text {meso }}\right)$ was calculated by subtracting the micropore volume from the total pore volume. The XRD patterns of the $\mathrm{MnO}_{2}$ were characterized by means of Rigaku DMAX-2000 diffractometer using a $\mathrm{Cu} \mathrm{K} \alpha$ source. The electrochemical measurements were tested by threeelectrode electrochemical cell on CHI660C Instrument.

2.4. Electrochemical Measurements. The $\mathrm{MnO}_{2}$ electrode was used as the working electrode, Pt plate as the counter, and a saturated calomel electrode (SCE) as the reference electrode. $0.5 \mathrm{M} \mathrm{Na}_{2} \mathrm{SO}_{4}$ solution was used as electrolyte. The electrodes were obtained by pressing electrode slurry formed by $\mathrm{MnO}_{2}$ (75 wt\%), PVdF (5 wt\%), and SuperP (20 wt\%) on Ti mesh at the pressure of $10 \mathrm{MPa}$.

The capacitance of the electrode material was determined by cyclic voltammetry between 0 and $0.9 \mathrm{~V}$. The mass specific capacitance was calculated according to the following formula:

$$
C=\frac{Q}{(\Delta V \cdot m)},
$$

where the charge $(Q)$ is half of the integrated area of the $C V$ curve and $m$ and $\Delta V$ refer to the mass of the electrode and the potential window, respectively.

\section{Results and Discussion}

3.1. XRD. Figure 1 shows the XRD pattern of the sample of blank prepared by the decomposition of $\mathrm{Mn}\left(\mathrm{NO}_{3}\right)_{2}$ directly without the addition of silica sol template. The reflections of the sample are found to be sharp, indicating the good crystallinity of the sample. And the crystal form is confirmed to be $\beta-\mathrm{MnO}_{2}$ corresponding to JCPDS number 72-1984.

Figure 2 shows the XRD patterns of the samples of MMO$x(x=1-6)$. The reflections of the samples are found to be consistent with those of the sample of blank, indicating the remains of the crystal structure of the samples. And the broader and weaker reflections of the samples suggest the decrease of the crystallinity of the samples.

3.2. Adsorption and Desorption Isotherms. Adsorption and desorption isotherms of the samples of blank and MMO$x(x=1-6)$ are shown in Figure 3 . We can see that there exist notable changes on the adsorption and desorption isotherms between the samples of blank and MMO- $x(x=$ $1-6)$. The nitrogen uptake of the sample of blank was nearly zero, indicating the nonporous nature of this material. The isotherms of MMO- $x(x=1-6)$ belong to type IV according to the IUPAC classification. The hysteresis loop on the isotherms suggests the capillary condensation occurring in mesopores and the limiting uptake occurring at high relative pressure. And the volume adsorbed of $\mathrm{N}_{2}$ of mesoporous $\mathrm{MnO}_{2}$

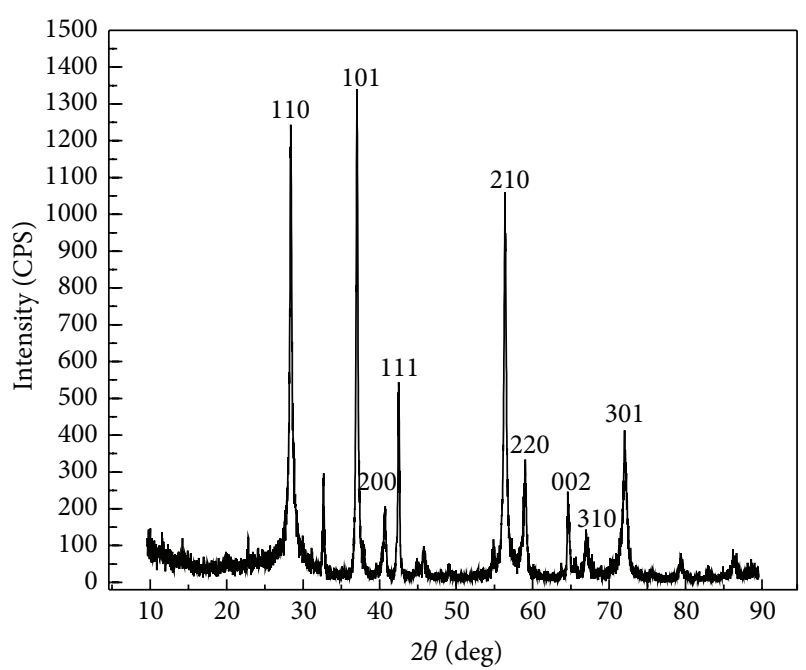

FIGURE 1: XRD pattern of the sample of blank.

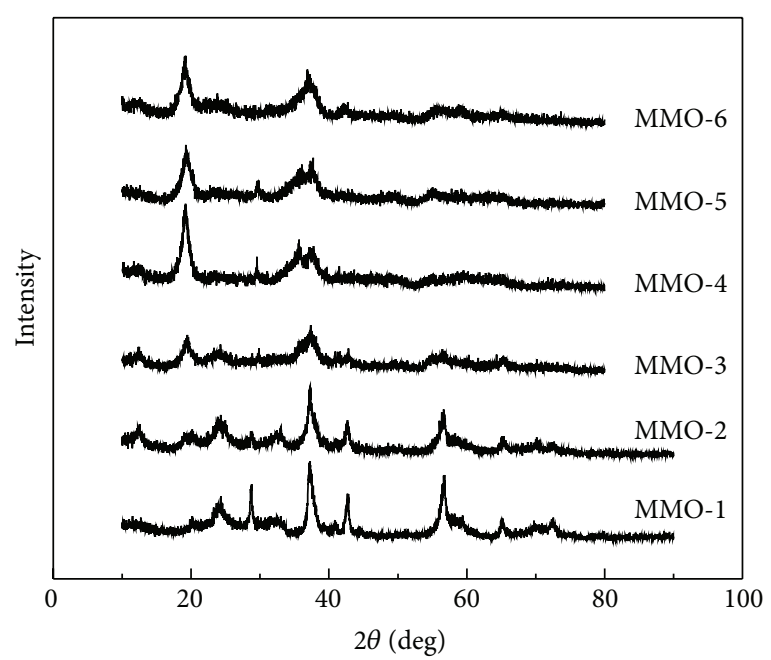

FIGURE 2: XRD patterns of the samples of MMO- $x(x=1-6)$.

TABLE 1: Pore characteristics of the mesoporous $\mathrm{MnO}_{2}$.

\begin{tabular}{lccc}
\hline Samples & $\begin{array}{c}S_{\mathrm{BET}} \\
\left(\mathrm{m}^{2} \mathrm{~g}^{-1}\right)\end{array}$ & $\begin{array}{c}V_{t} \\
\left(\mathrm{~cm}^{3} \mathrm{~g}^{-1}\right)\end{array}$ & $\begin{array}{c}\text { Mean pore } \\
\text { size }(\mathrm{nm})\end{array}$ \\
\hline Blank & 0.55 & - & - \\
MMO-1 & 22.65 & 0.0663 & 11.71 \\
MMO-2 & 39.84 & 0.1168 & 11.73 \\
MMO-3 & 63.86 & 0.1726 & 10.81 \\
MMO-4 & 61.30 & 0.2062 & 13.46 \\
MMO-5 & 81.81 & 0.2467 & 12.06 \\
MMO-6 & 89.73 & 0.2655 & 11.83 \\
\hline
\end{tabular}

increases with the increase of the mass ratio of silica sol to $\mathrm{Mn}\left(\mathrm{NO}_{3}\right)_{2}$.

The pore characteristics, namely, BET surface area, total pore volume, and mean pore size determined from the $\mathrm{N}_{2}$ adsorption and desorption isotherms are shown in Table 1. 


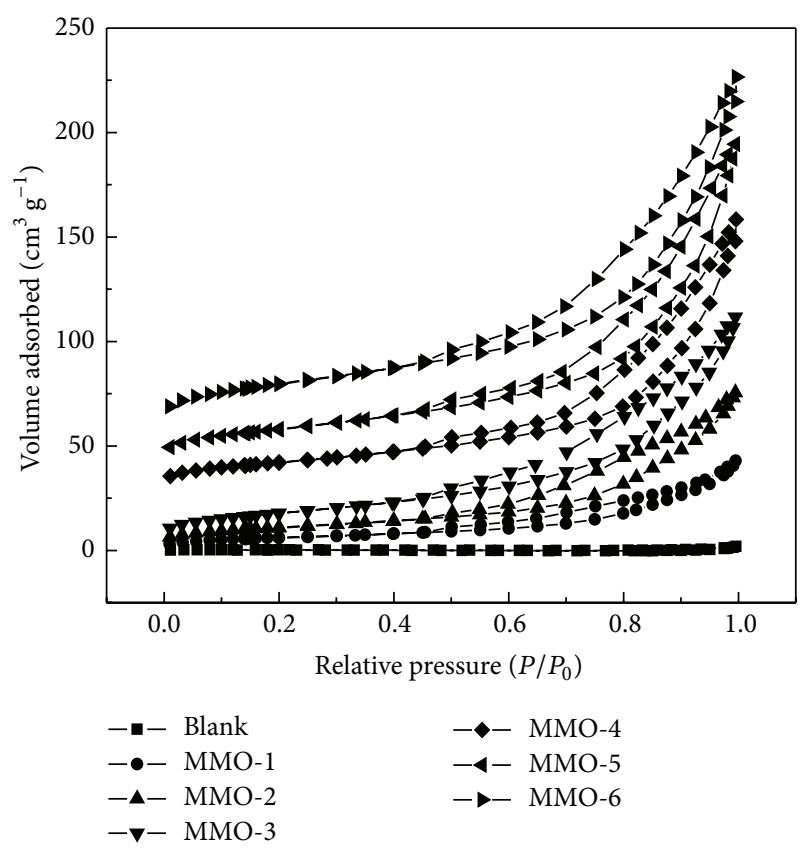

FIGURE 3: Adsorption and desorption isotherms of the samples of blank and MMO- $x(x=1-6)$. The isotherms of MMO-4, MMO-5, and MMO-6 were offset vertically by 25,35 , and $55 \mathrm{~cm}^{3} \mathrm{~g}^{-1}$ STP.

The BET surface area and total pore volume increases with the increase of the mass ratio of silica sol to manganese source. We can safely draw a conclusion that, in the silica sol/ $\mathrm{Mn}\left(\mathrm{NO}_{3}\right)_{2}$ ratio studied, the porosity of the mesoporous $\mathrm{MnO}_{2}$ is improved greatly with the increase of silica sol/Mn $\left(\mathrm{NO}_{3}\right)_{2}$ ratio, demonstrating that silica particle effectively functions as template and pore-generators.

Figure 4 shows the pore size distributions of the sample of blank and MMO- $x(x=1-6)$. The results show that the samples are mesoporous except the sample of blank, which is consistent with that of the result of adsorption and desorption isotherms. The predominant pore size of the samples is found to be in the range of $6 \sim 8 \mathrm{~nm}$, suggesting some shrinkage for the mean $10 \mathrm{~nm}$ of the particle size of the silica particle used as template. Furthermore, the predominant pore size of the samples increases with the increase of the amount of silica sol added.

\subsection{Electrochemical Measurements. Figure 5 presents CVs of} the samples of blank and MMO- $x(x=1-6)$ at the scan rate of $5 \mathrm{mV} \mathrm{s}^{-1}$. The steady-state voltammograms of all the samples exhibit a rectangular image with broad peaks observed, corresponding to a typical pseudocapacitive behavior where the current flow is independent of the electrode potential.

Figure 6 illustrates the effect of scan rate on the cyclic voltammetry behavior of the sample of MMO-4 electrode in the $0.5 \mathrm{M} \mathrm{Na}_{2} \mathrm{SO}_{4}$ electrolyte. The rectangular shape of the voltammogram at lower scan rate suggests the ideal pseudocapacitive behavior of the electrode. However, at higher scan rate the voltammograms of the electrode deviate

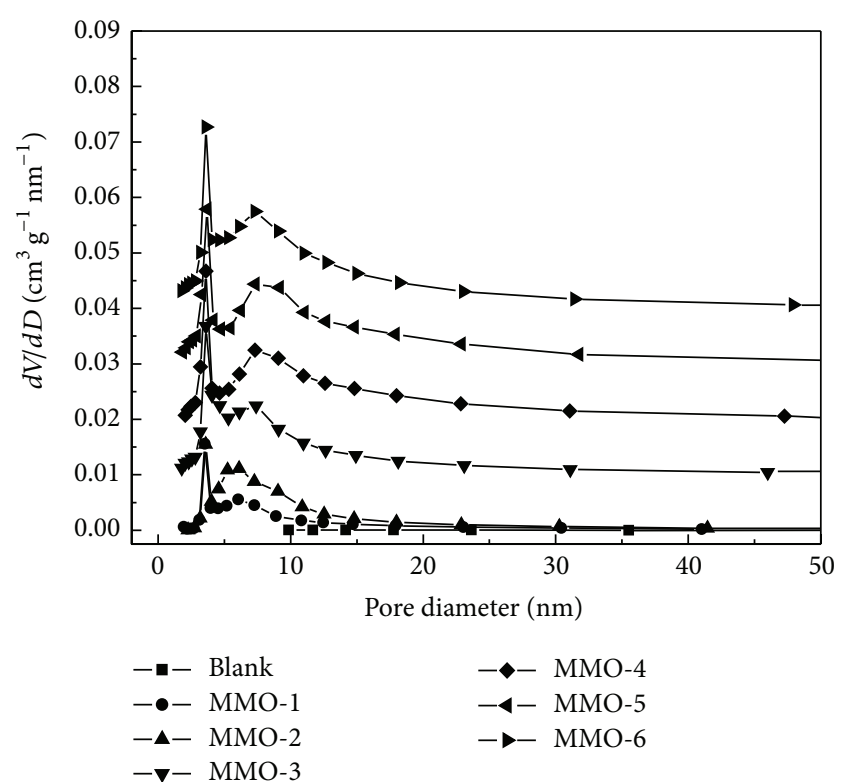

FIGURE 4: Mesopore size distributions of the samples of blank and MMO- $x(x=1-6)$.

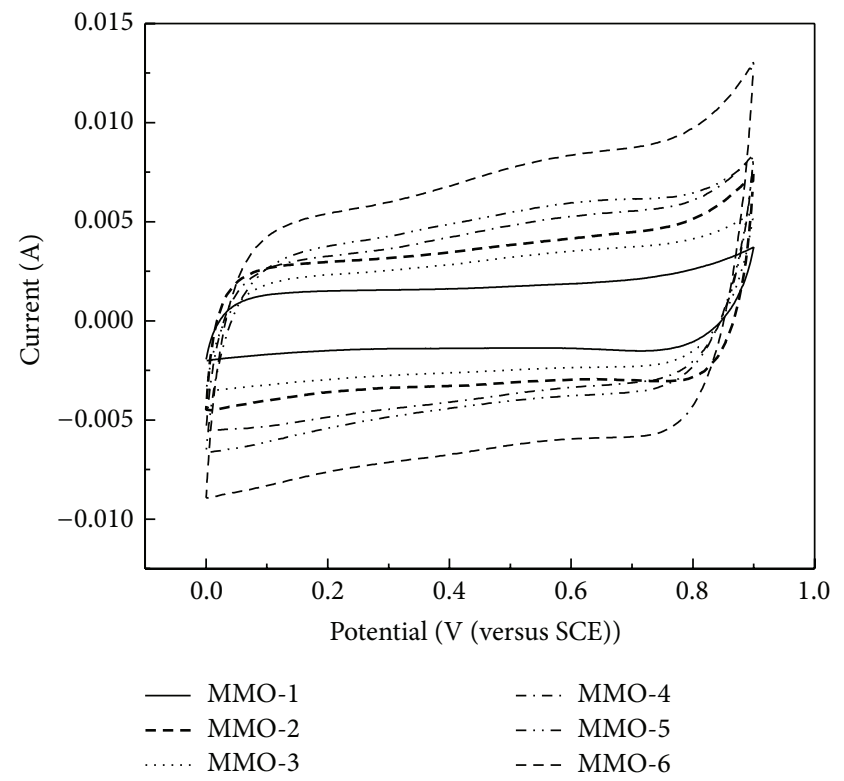

Figure 5: CVs of the samples of blank and MMO- $x(x=1-6)$ at the scan rate of $5 \mathrm{mV} / \mathrm{s}$.

from this shape due to slow diffusion within the material particles [15].

Figure 7 shows the influence of scan rate on the capacitance recorded with scan rates from 5 to $200 \mathrm{mV} / \mathrm{s}$ for the samples of blank and MMO-x $(x=1-6)$. The specific capacitances at the scan rate of $5 \mathrm{mV} / \mathrm{s}$ calculated from the $\mathrm{CV}$ curve of the sample of $\mathrm{MMO}-4$ are the highest $(163.2 \mathrm{~F} / \mathrm{g})$, in comparison with $19.3 \mathrm{~F} / \mathrm{g}$ of that of the sample of blank, suggesting the important role of pore-forming using silica sol as template. As shown in the figure, the 


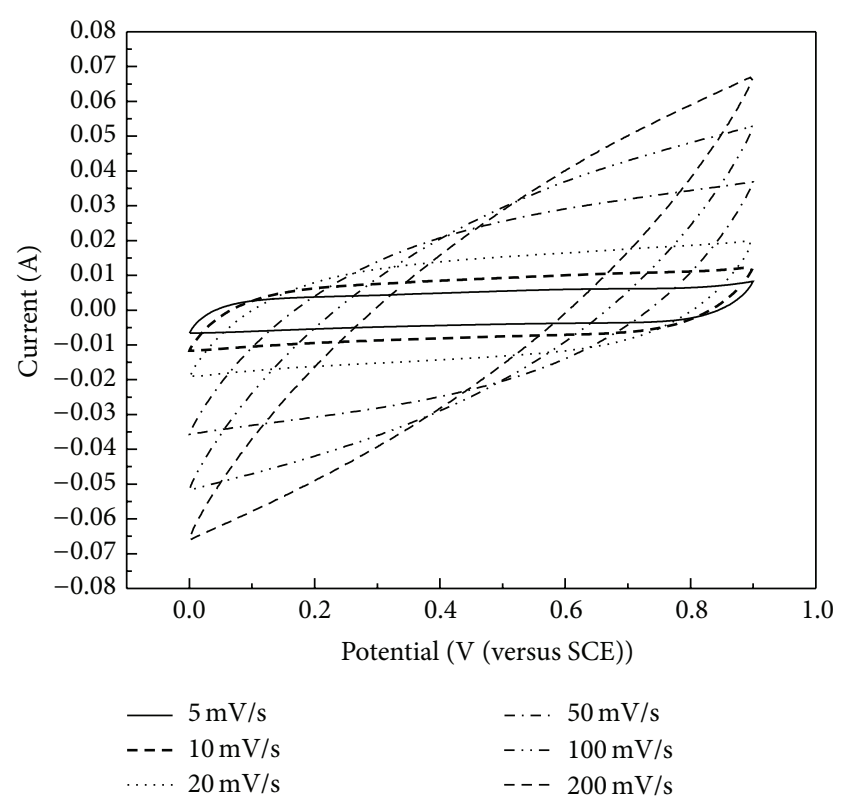

FIgURE 6: CVs of the sample of MMO-4 at different scan rates.

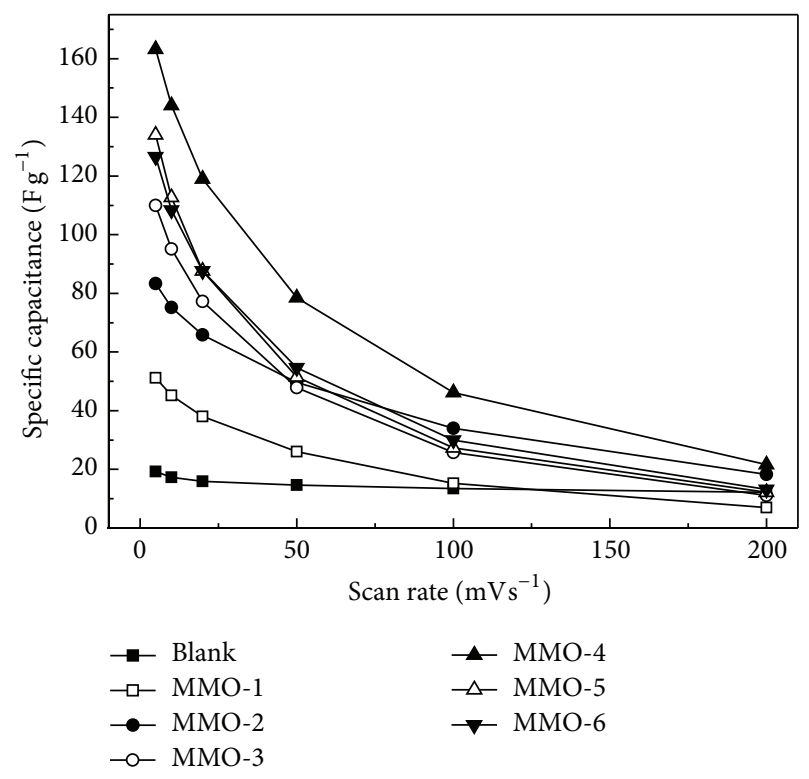

FIGURE 7: Specific capacitance of the samples of blank and MMO- $x$ $(x=1-6)$ at different scan rates.

specific capacitances of the samples decrease as the scan rate increases. As the potential scan rate is raised to $200 \mathrm{mV} / \mathrm{s}$, the specific capacitances of the sample of blank and MMO-4 are $12.2 \mathrm{~F} / \mathrm{g}$ and $21.6 \mathrm{~F} / \mathrm{g}$, respectively. The great improvement of specific capacitance is probably due to the enlarged activated surface area after template is added.

The charge-discharge behavior of the sample of MMO-4 was examined by chronopotentiometry. Figure 8 shows the charge/discharge behavior of the electrode of MMO-4. The linear and symmetric charge/discharge curves indicate good capacitive and revisable behavior.

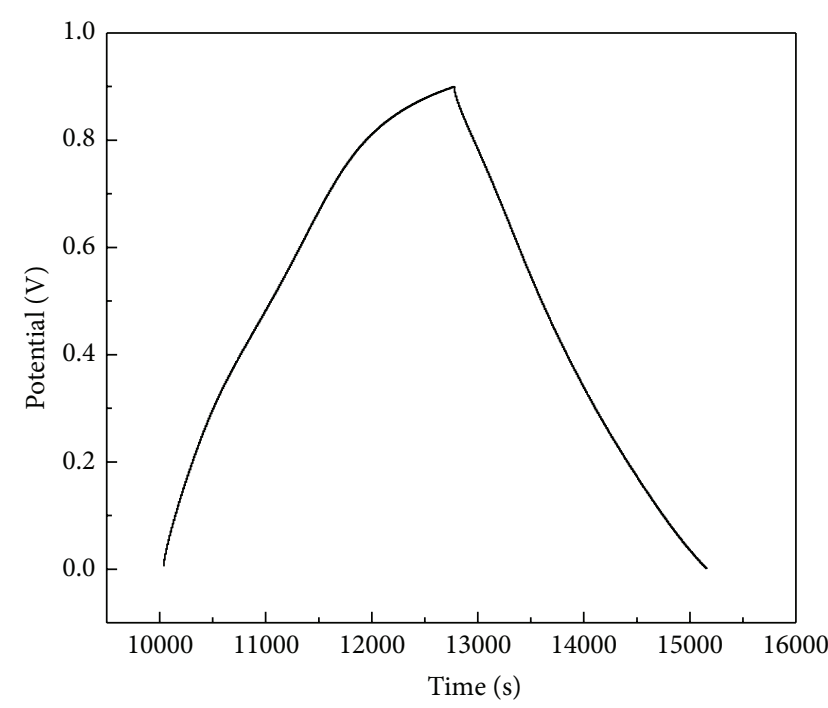

Figure 8: Charge-discharge curve of the sample of MMO-4 at the current density of $0.5 \mathrm{~mA} \mathrm{~cm}^{-2}$.

\section{Conclusions}

A series of mesoporous $\mathrm{MnO}_{2}$ with different surface areas (from 22.65 to $89.73 \mathrm{~m}^{2} / \mathrm{g}$ ) have been synthesized by silica sol template method by utilizing silica sol as template and $\mathrm{Mn}\left(\mathrm{NO}_{3}\right)_{2}$ as manganese source. The results of XRD characterization show that the crystal type of the samples of blank and MMO- $x(x=1-6)$ is confirmed to be $\beta-\mathrm{MnO}_{2}$ and crystallinity of MMO- $x(x=1-6)$ decreases due to the formation of mesopore. It is found that the BET surface area and total pore volume increase with the increase of the mass ratio of silica sol to manganese source. And silica particle effectively functions as template and pore-generators.

The results of electrochemical performance show that the specific capacitances of the sample of MMO-4 at the scan rate of $5 \mathrm{mV} / \mathrm{s}$ are the highest $(163.2 \mathrm{~F} / \mathrm{g})$, in comparison with $19.3 \mathrm{~F} / \mathrm{g}$ of that of the sample of blank, suggesting the important role of pore-forming using silica sol as template. As the potential scan rate is raised to $200 \mathrm{mV} / \mathrm{s}$, the specific capacitances of the sample of blank and MMO-4 are $12.2 \mathrm{~F} / \mathrm{g}$ and $21.6 \mathrm{~F} / \mathrm{g}$, respectively. The great improvement of specific capacitance is probably due to the enlarged activated surface area after template is added.

\section{Conflict of Interests}

The authors declare that there is no conflict of interests regarding the publication of this paper.

\section{Acknowledgment}

This project was supported by Shanghai Municipal Commission of Economy and Informatization (CXY-2013-12). 


\section{References}

[1] C. C. Chen, C.-Y. Yang, and C.-K. Lin, "Improved pseudocapacitive performance of manganese oxide films synthesized by the facile sol-gel method with iron acetate addition," Ceramics International, vol. 39, no. 7, pp. 7831-7838, 2013.

[2] D. Yan, Z. Guo, G. Zhu, Z. Yu, H. Xu, and A. Yu, " $\mathrm{MnO}_{2}$ film with three-dimensional structure prepared by hydrothermal process for supercapacitor," Journal of Power Sources, vol. 199, pp. 409-412, 2012.

[3] J. Yang, L. Lian, H. Ruan, F. Xie, and M. Wei, "Nanostructured porous $\mathrm{MnO}_{2}$ on $\mathrm{Ni}$ foam substrate with a high mass loading via a CV electrodeposition route for supercapacitor application," Electrochimica Acta, vol. 136, pp. 189-194, 2014.

[4] S. Devaraj and N. Munichandraiah, "Electrochemical supercapacitor studies of nanostructured $\alpha-\mathrm{MnO}_{2}$ synthesized by microemulsion method and the effect of annealing," Journal of the Electrochemical Society, vol. 154, no. 2, pp. A80-A88, 2007.

[5] P. K. Nayak and N. Munichandraiah, "Rapid sonochemical synthesis of mesoporous $\mathrm{MnO}_{2}$ for supercapacitor applications," Materials Science and Engineering B, vol. 177, no. 11, pp. 849854, 2012.

[6] X. Hong, G. Zhang, Y. Zhu, and H. Yang, "Sol-gel synthesis and characterization of mesoporous manganese oxide," Materials Research Bulletin, vol. 38, no. 13, pp. 1695-1703, 2003.

[7] T. Xue, C.-L. Xu, D.-D. Zhao, X.-H. Li, and H.-L. Li, “Electrodeposition of mesoporous manganese dioxide supercapacitor electrodes through self-assembled triblock copolymer templates," Journal of Power Sources, vol. 164, no. 2, pp. 953-958, 2007.

[8] M.-W. Xu, D.-D. Zhao, S.-J. Bao, and H.-L. Li, "Mesoporous amorphous $\mathrm{MnO}_{2}$ as electrode material for supercapacitor," Journal of Solid State Electrochemistry, vol. 11, no. 8, pp. 11011107, 2007.

[9] P. K. Nayak and N. Munichandraiah, "Mesoporous $\mathrm{MnO}_{2}$ synthesized by using a tri-block copolymer for electrochemical supercapacitor studies," Microporous and Mesoporous Materials, vol. 143, no. 1, pp. 206-214, 2011.

[10] S. Li, L. Qi, L. Lu, and H. Wang, "Carbon spheres-assisted strategy to prepare mesoporous manganese dioxide for supercapacitor applications," Journal of Solid State Chemistry, vol. 197, pp. 29-37, 2013.

[11] S. A. Johnson, P. J. Ollivier, and T. E. Mallouk, "Ordered mesoporous polymers of tunable pore size from colloidal silica templates," Science, vol. 283, no. 5404, pp. 963-965, 1999.

[12] J. E. G. J. Wijnhoven and W. L. Vos, "Preparation of photonic crystals made of air spheres in titania," Science, vol. 281, no. 5378, pp. 802-804, 1998.

[13] J. Zhao, C. Lai, Y. Dai, and J. Xie, "Pore structure control of mesoporous carbon as supercapacitor material," Materials Letters, vol. 61, no. 23-24, pp. 4639-4642, 2007.

[14] G. L. Egan, J.-S. Yu, C. H. Kim, S. J. Lee, R. E. Schaak, and T. E. Mallouk, "Nanoscale metal replicas of colloidal crystals," Advanced Materials, vol. 12, no. 14, pp. 1040-1042, 2000.

[15] S. Sarangapani, B. V. Tilak, and C.-P. Chen, "Materials for electrochemical capacitors theoretical and experimental constraints," Journal of the Electrochemical Society, vol. 143, no. 11, pp. 3791-3799, 1996. 

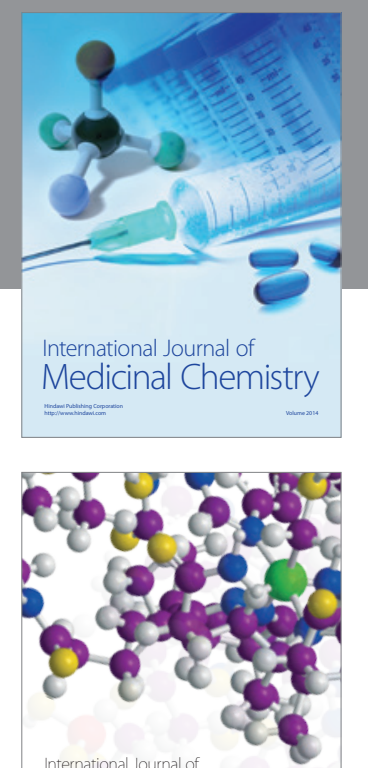

\section{Carbohydrate} Chemistry

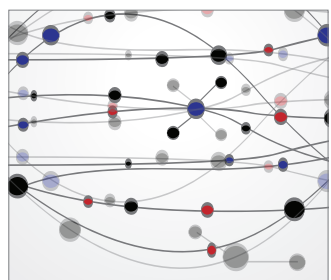

The Scientific World Journal
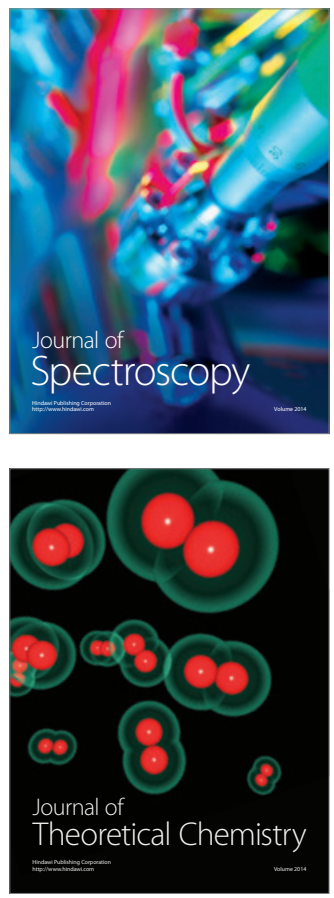
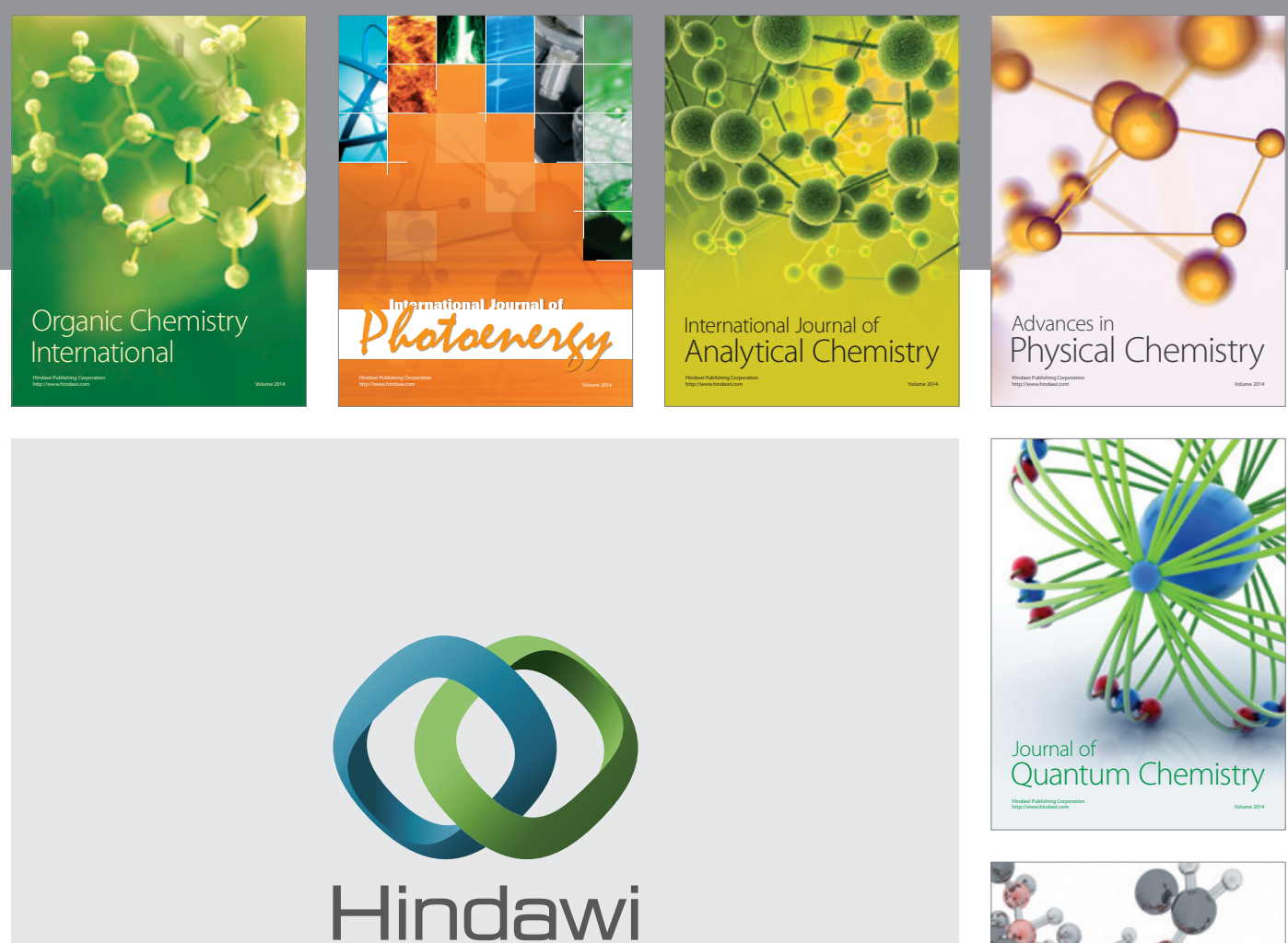

Submit your manuscripts at

http://www.hindawi.com

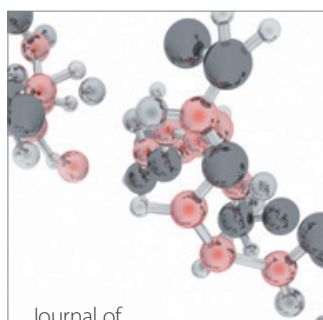

Analytical Methods

in Chemistry

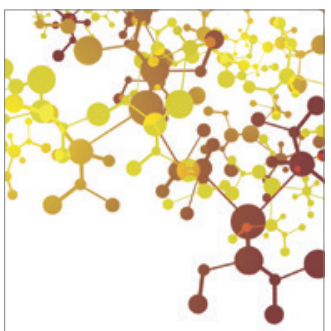

Journal of

Applied Chemistry

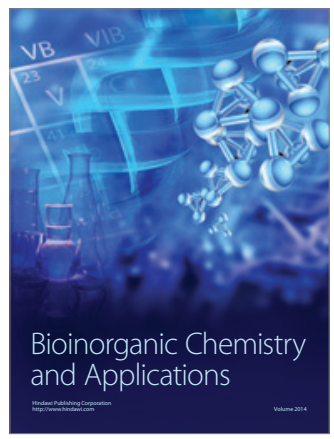

Inorganic Chemistry
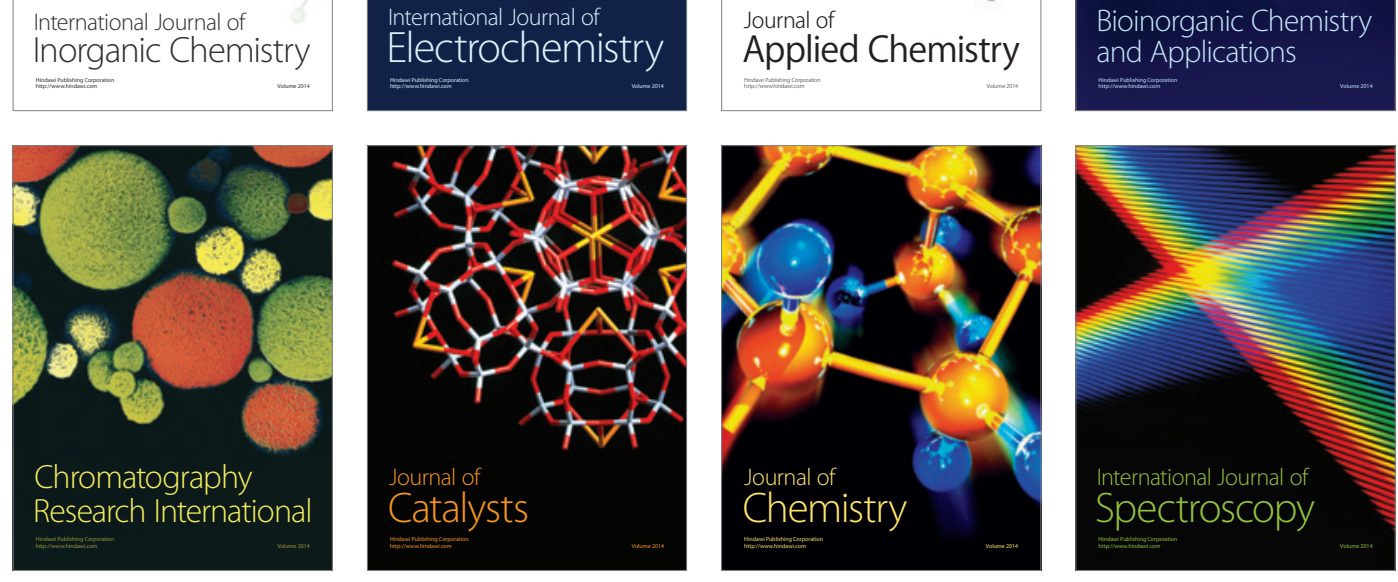